\title{
THE EFFECT OF QUERCETIN AND GALANGIN ON GLUTATHIONE REDUCTASE
}

\author{
Helena Paulíková, Elena Berczeliová
}

\begin{abstract}
Department of Biochemistry and Microbiology, Faculty of Chemical and Food Technology, Slovak Technical University, Bratislava

e-mail: helena.paulikova@stuba.sk
\end{abstract}

Received: June 10, 2005; Accepted: September 25, 2005

Key words: Flavonoids/ Glutathione reductase/ Diaphorase activity.

Quercetin and galangin can change the activity of glutathione reductase. Quercetin (a catechol structure in the B-ring) and galangin (any hydroxyl group in the B-ring) have different biological activities but, both possess high antioxidant abilities. Quercetin during the antioxidative action, is converted into an oxidized products (o-semiquinone and $o$-quinone), and subsequently glutathionyl adducts may be formed or SH-enzyme can be inhibited. We have tried to see whether inhibition of glutathione reductase (GR) can be influenced by preincubation of enzyme with NADPH (a creation of reduced form of enzyme, $\mathrm{GRH}_{2}$ ) and whether diaphorase activity of the enzyme is decreased by these flavonoids. The results confirmed that quercetin inhibits $\mathrm{GRH}_{2}$ and inhibition is reduced by addition of EDTA or $N$-acetylcysteine. Both of flavonoids have no effect on diaphorase activity of glutathione reductase and this enzyme could increase the production of free radicals by catalysis of reduction of $o$-quinone during action of quercetin in vivo.

\section{INTRODUCTION}

Flavonoids are frequently components of human diet and multiple mechanisms have been identified for their biological and pharmacological effects ${ }^{1-3}$. The major effects of flavonoids may be the result of radical scavenging. Another possible mechanism by which flavonoids act is through interaction with various enzyme systems. Their cellular activities are ambiguous, with some activities being mutually opposing, for example, flavonoids protect cells from "oxidative stress" however pro-oxidant properties of these compounds could contribute to tumor cell apoptosis or genotoxicity ${ }^{4-6}$. The intracellular ratio GSH/ GSSG is an important indicator of the cellular redox state $^{7}$. Flavonoids can modify redox state of glutathione, GS-flavonoid conjugate or oxidation of GSH to GSSG can arise from reactions of GSH with $o$-semiquinone ${ }^{8}$. In addition the effects of flavonoids on the glutathionerelated enzymes have been demonstrated ${ }^{9-12}$. Glutathione reductase (EC 1.6.4.2, GR) has a prominent role because the product of GSH oxidation, GSSG, is rapidly converted back to GSH by this enzyme. Flavonoids have been described to inhibit glutathione reductase isolated from different sources ${ }^{9-12}$. Elliott et al. ${ }^{9}$ shown that the most potent inhibitors of yeast glutathione reductase are luteolin and quercetin and they estimated the $\mathrm{IC}_{50}$ values $(170 \mu \mathrm{M}$, resp. $280 \mu \mathrm{M})$.

Recently we have studied the modulation of cis-Pt induced apoptosis by quercetin and galangin. Flavonoids (at low concentrations) differentially modulated cis-Ptinduced apoptosis and the involvenment of intracellular glutathione was observed ${ }^{13,14}$. Our work hypothesis is that one of the reason of the diverse action of quercetin and galangin is related with uneven effect of flavonoids on the glutathione reductase.

In this paper we have investigated the influence of these flavonoids at low concentration (from 25 to $100 \mu \mathrm{M}$ ) on the activities of the glutathione reductase from yeast, GSSG-reductase activity and diaphorase activity of GR has been examined. Yeast GR and human GR are similar in topology ${ }^{15,16}$, thus allowing the use the yeast enzyme as a model for the inhibition studies.

\section{MATERIAL AND METHODS}

\section{Chemicals}

Glutathione reductase from baker's yeast, NADPH, reduced and oxidised forms of glutathione (GSH and GSSG), $N$-acetylcysteine (NAC) and flavonoids (quercetin (QU), galangin (GA)) were purchased from SigmaAldrich Corp. (St. Louis, MO, USA). Flavonoids were dissolved in dimethyl sulphoxide (DMSO, Sigma). The stock solutions of flavonoids $(0.1 \mathrm{M})$ were stored at $-20{ }^{\circ} \mathrm{C}$. EDTA, 2,6-Dichlorophenolindophenol (DPIP) and all other chemicals were obtained from Lachema Brno (Czech Republic).

\section{Enzyme assays}

Glutathione reductase activity was measured by monitoring the oxidation of NADPH at $340 \mathrm{~nm}$ at $25{ }^{\circ} \mathrm{C}$ for 3 min (PU 8750 UV/VIS Scanning Spectrophotometer PHILIPS). The standard GR reaction medium contained $100 \mathrm{mM}$ phosphate buffer, $\mathrm{pH}$ 7.4, 5-100 $\mu \mathrm{M}$ NADPH, $1 \mathrm{mM} \mathrm{GSSG}$ and $20 \mu \mathrm{l}$ of dilute GR. Enzyme suspension (198 U/mg prot) was diluted 200-fold with the $50 \mathrm{mM}$ 
phosphate buffer and kept at $4{ }^{\circ} \mathrm{C}$. Total volume was $2 \mathrm{ml}$ and the reaction was started by adding NADPH or GSSG, the initial velocity of GR reaction was measured by the slope of recorded tracing. Glutathione reductase activity was expressed as nmole NADPH oxidised $/ \mathrm{min} / \mathrm{mg}$ protein, using $\varepsilon=6.22 \mathrm{mM}^{-1} \cdot \mathrm{cm}^{-1}$.

GR-diaphorase activity was measured by the rate of DPIP reduction at $600 \mathrm{~nm}\left(\varepsilon=19.0 \mathrm{mM}^{-1} \mathrm{~cm}^{-1}\right)$ using NADPH as electron donor. The reaction medium contained 0.1 M phosphate buffer, $\mathrm{pH}$ 7.4, 0.2 mM NADPH and GR. The action was started adding DPIP (40 $\mu \mathrm{M})$. DT-diaphorase activity was expressed as nmol DPIP reduced $/ \mathrm{min} / \mathrm{mg}$ protein.

All data points in the figure and tables represent the mean of three or more experiments \pm SD.

\section{RESULTS AND DISCUSSION}

Glutathione reductase is ubiquitous FAD-containing enzyme. It catalyses the reaction

$$
\begin{aligned}
& \mathrm{GR}+\mathrm{NADPH} \rightleftharpoons \mathrm{GRH}_{2}+\mathrm{NADP} \\
& \mathrm{GRH}_{2}+\mathrm{GSSG} \rightleftharpoons \mathrm{GR}+2 \mathrm{GSH},
\end{aligned}
$$

where the intermediate $\mathrm{GRH}_{2}$ is the stable 2-electron reduced form of the enzyme. NADPH reacting first with catalytic site of the enzyme to produce the $\mathrm{GRH}_{2}$ which in turn binds and reduces GSSG (bi-bi ping-pong mechanism $)^{16}$. The enzyme has diaphorase activity except GSSG-reductase activity. Enzyme is inactivated by $\mathrm{SH}$-reagents, e.g. $N$-ethylmaleimide strongly influenced GSSG-reduction but the effect on diaphorase activity is very slight ${ }^{17,18}$. If only quercetin could modify enzyme at the intermadiate state - $\mathrm{GRH}_{2}$ than preincubation of GR with QU increases its inhibition effect and contrary inhibition efficiency of galangin could not be dependent on preincubation of enzyme with NADPH.

At first the effect of quercetin and galangin on GSSGreductase activity has been estimated at low concentration $(25 \mu \mathrm{M})$. Flavonoids were added to the enzyme whithout or after preincubation of enzyme with NADPH (1 min). The inhibition effect of galangin was weak and did not depend on preincubation with the coenzyme (Table 1).

Table 1. The effects of flavonoids at $25 \mu \mathrm{M}$ concentration on GR activity without and after 1 min preincubation with NADPH

\begin{tabular}{|l|c|c|}
\hline \multirow{2}{*}{} & \multicolumn{2}{|c|}{ Remaining activity [\%] } \\
\cline { 2 - 3 } & preincubation & $\begin{array}{c}\text { without } \\
\text { preincubation }\end{array}$ \\
\hline control & 100 & 100 \\
\hline Quercetin & $41.8 \pm 0.8$ & $78.3 \pm 0.9$ \\
\hline Galangin & $65.0 \pm 0.7$ & $68.6 \pm 0.9$ \\
\hline
\end{tabular}

Remaining activity of GR was measured as described in "Materials and Methods", $100 \mu \mathrm{M}$ NADPH and $1 \mathrm{mM}$ GSSG were used. GR activity of control: $24.62 \pm 0.12 \mu \mathrm{mol}$ $\mathrm{NADPH} / \mathrm{min} / \mathrm{mg}$ protein.
As seen in Table 1, quercetin is a potent inhibitor but its effect without preincubation with NADPH was obscure. GSSG-reductase activity decreased about $60 \%$ only after preincubation of GR with NADPH.

The kinetic studies showed that quercetin inhibition could be an acompetetive with respect to NADPH but only at low concentration of NADPH $(<35 \mu \mathrm{M})$ (Fig. 1 inside). The inhibition effect was considerably higher when NADPH was kept at higher concentration $(\geq 50 \mu \mathrm{M})$ (Fig. 1).

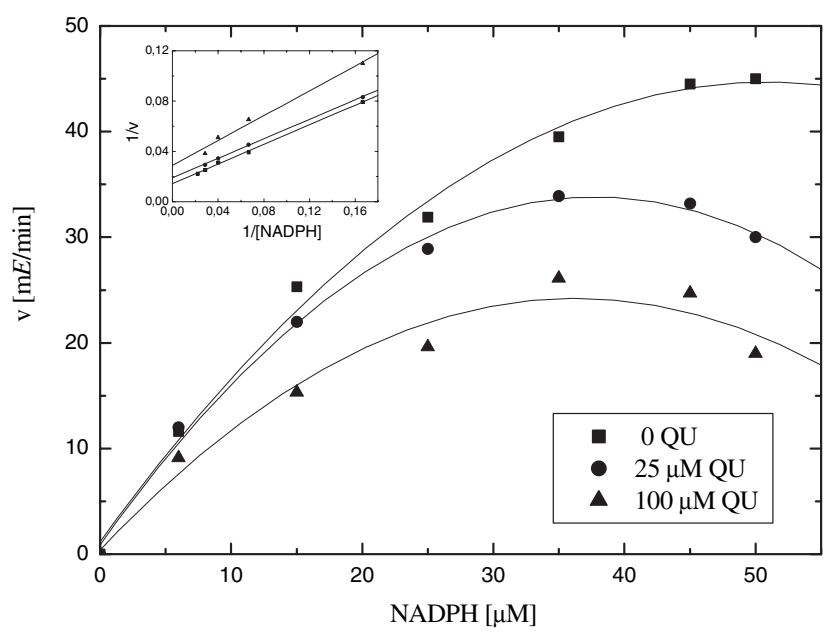

Fig. 1. The effect of quercetin on enzyme kinetic plots. Enzyme activity was measured as described in "Materials and Methods" at different NADPH concentration and at $1 \mathrm{mM}$ GSSG. Inset: LineweaverBurk plot. Values of y-axis are absorbance increments at $340 \mathrm{~nm}$ for $1 \mathrm{~min}$ and reciprocal of absorbance increments (Lineweaver-Burk plot).

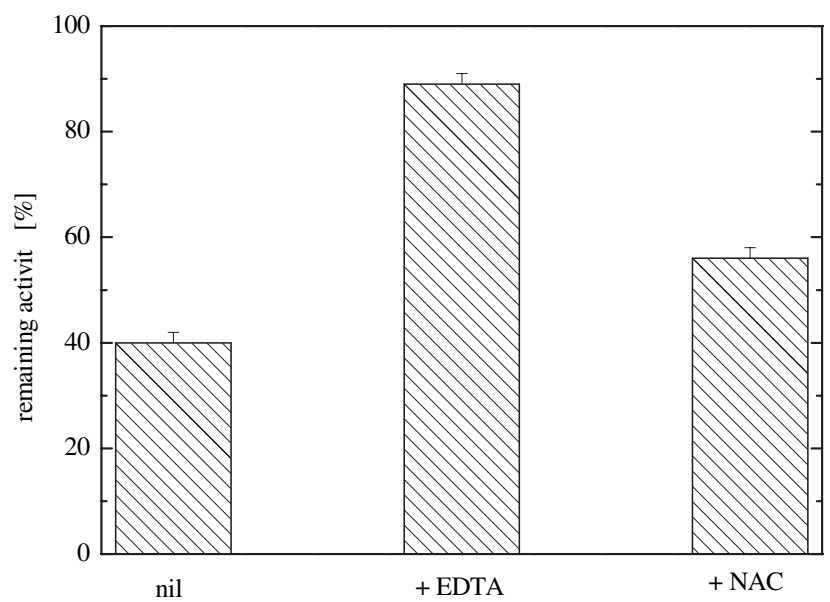

Fig. 2. Effects of EDTA and NAC on quercetin inhibition of glutathione reductase. The enzyme activity was measured as described in "Materials and Methods", $100 \mu \mathrm{M}$ NADPH and $1 \mathrm{mM} \mathrm{GSSG}$ were used. $25 \mu \mathrm{M}$ QU was added after 1 min preincubation of the enzyme with NADPH and $200 \mu \mathrm{M}$ NAC or $200 \mu \mathrm{M}$ EDTA. GR activity of control: $24.42 \pm 0.22 \mu \mathrm{mol} \mathrm{NADPH} / \mathrm{min} / \mathrm{mg}$ protein. 


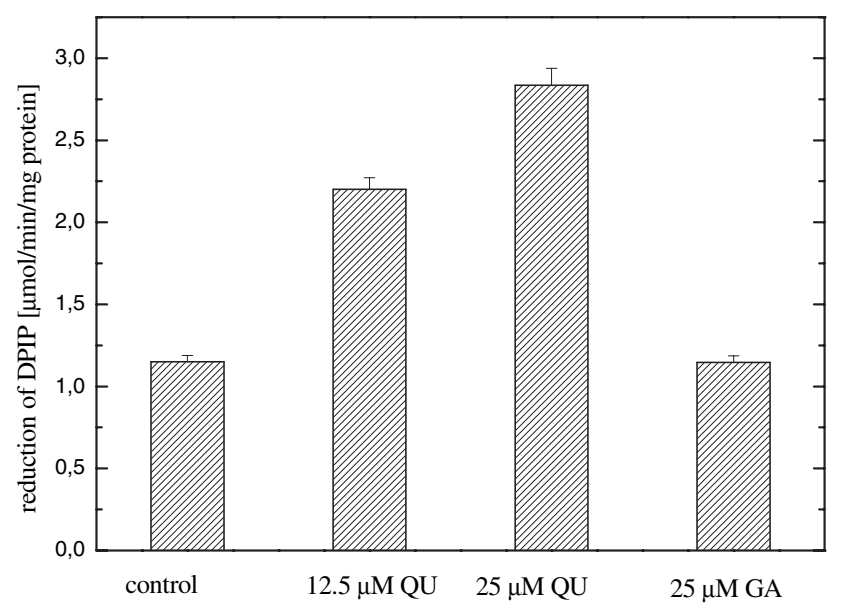

Fig. 3. Effects of quercetin and galangin on diaphorase activity of glutathione reductase. Diaphorase activity was measured as described in "Materials and Methods".

Two possible modes of quercetin action could be considered, formation of ROS in the presence of catalytical amounts of metal ions and irreversible modification of the enzyme by the oxidized products from this catecholcontaining flavonoid. Transition metal ions are known to catalyze the oxidation of quinols ${ }^{19}$. A quite similar phenomenon has been demonstrated for the interaction of rabbit reticulocyte 15 -lipoxygenase- 1 with flavonoids ${ }^{20}$.

As seen in Fig. 2, the elimination of trace of metal ions by the addition of $200 \mu \mathrm{M}$ EDTA protected GR against inhibition by $25 \mu \mathrm{M}$ quercetin. When a $N$-acetylcysteine $(200 \mu \mathrm{M})$ was used for a protection of GR, the enzyme activity was protected only partially (Fig. 2.).

One can assume that the formation of erroneous disulfide at the active site of the reduced enzyme or modification of cysteine residues by quercetin should not influence diaphorase activity of glutathione reductase. We have expected that the enzyme will be able to keep full diaphorase activity in the presence of flavonoids. GR has been preincubated with NADPH for $1 \mathrm{~min}$ and quercetin or galangin were added. Both flavonoids had no significant effect on diaphorase activity (Fig. 3). DCIP was used as a substrate and because quercetin is able to reduce DCIP (B-ring of quercetin is oxidised to $o$-quinone, galangin does not react with DCIP) foremost the reduction of DCIP by quercetin was observed.

The GSSG-reductase activity was decreased by flavonoids while the diaphorase activity remained unaltered. We suppose that the inhibition by QU is a site-specific process and that exclude the enzyme FAD-domain, as indicated by unaltered GR diaphorase activity. Quercetin may react with sulfhydryl groups of vicinal cysteine residues (GRH2) and our results (decrease of inhibition by addition of NAC) may be in line with the formation of QU-thiol conjugates under conditions of catalysis (Fig. 2). The irreversible inhibition of GR by flavonoids has been demonstarted by Zhang et al. ${ }^{10}$
The cytotoxic action of quercetin was suspected to result from its pro-oxidant ability ${ }^{21}$ and Metodieva et al. ${ }^{8}$ suggested that DT-diaphorase is involved in prooxidant action of quercetin. Flavonoids did not alter diaphorase activity of GR, therefore the role of glutathione reductase in the depletion of NADPH during incubation of cells with some flavonoids should be considered.

\section{ACKNOWLEDGEMENT}

This work was supported by the grant of the Slovak Grant Agency number 1/1173/04.

\section{REFERENCES}

1. Birt DF, Hendrich S, Wang W. (2001) Dietary agents in cancer prevention: flavonoids and isoflavonoids. Pharmacol Ther 90, 157-77.

2. Havsteen BH. (2002) The biochemistry and medical significance of the flavonoids. Pharmacol Ther 96, 67-202.

3. Ren W, Qiao Z, Wang H, Zhu L, Zhang L. (2003) Flavonoids: Promising anticancer agents. Med Res Rev 4, 519-34.

4. Rietjens IMCM, Boersma MG, de Haan L, Spenkelink B, Awad HM, Cnubben NHP, van Zanden JJ, van der Woude H, Alink GM, Koeman JH. (2002) The pro-oxidant chemistry of the natural antioxidants vitamin C, vitamin E, carotenoids and flavonoids. Environ Toxicol Pharmacol 11, 321-33.

5. Galati G, Sabzevari O, Wilson JX, O’Brien PJ. (2002) Prooxidant activity and cellular effects of the phenoxyl radicals of dietary flavonoids and other polyphenolics. Toxicology 177, 91-104.

6. Moridani MY, Galati G, O’Brien PJ. (2002) Comparative quantitative structure toxicity relationships for flavonoids evaluated in isolated rat hepatocytes and HeLa tumor cells. Chem-Biol Interact 139, 251-64.

7. Schafer FQ, Buettner GR. (2001) Redox environment of the cell as viewed through the redox state of the glutathione disulfide/glutathione couple. Free Radic Biol Med 30, 1191-212.

8. Metodiewa D, Jaiswal AK, Cenas N, Dickancaite E, Segura-Aguilar J. (1999) Quercetin may act as a cytotoxic prooxidant after its metabolic activation to semiquinone and quinoidal product. Free Radic Biol Med 26, 107-16.

9. Elliott AJ, Scheiber SA, Thomas C, Pardini RS. (1992) Inhibition of glutathione reductase by flavonoids: A structure-activity study. Biochem Pharmacol 44, 1603-8.

10. Zhang K, Yang EB, Tang WY, Wong KP, Mack P. (1997) Inhibition of glutathione reductase by plant polyphenols. Biochem Pharmacol $54,1047-53$.

11. Iio M, Kawaguchi H, Sakota Y, Otonari J, Nitahara H. (1993) Effects of Polyphenols, including flavonoids, on glutathione Stransferase and glutathione reductase. Biosci Biotech Biochem 57, 1678-80.

12. Kurata M, Suzuki M, Takeda K. (1992) Effects of phenol compounds, glutathione analogues and a diuretic drug on glutathione S-transferase, glutathione reductase and glutathione peroxidase from canine erythrocytes. Comp Biochem Physiol B. 103, 863-7.

13. Cipak L, Rauko P, Miadoková E, Cipaková I, Novotný L. (2003) Effects of flavonoids on cisplatin-induced apoptosis of HL-60 and L1210 leukemia cells. Leuk Res 27, 65-72.

14. Cipak L, Berczeliová E, Paulíková H.. (2003) Effects of flavonoids on glutathione and glutathione-related enzymes in cisplatin-treated L1210 leukemia cells. Neoplasma 50, 444-47.

15. Collinson LP, Dawes IW. (1995) Isolation, characterization and overexpression of the yeast gene, GLR1, encoding glutathione reductase. Gene 156, 123-27. 
16. Pai EF, Schulz GE. (1983) The catalytic mechanism of glutathione reductase as derived from $\mathrm{x}$-ray diffraction analyses of reaction intermediates. J Biol Chem 258, 1752-7.

17. Karplus PA, Krauth-Siegel RL, Schirmer RH, Schulz GE. (1988) Inhibition of human glutathione reductase by the nitrosourea drugs 1,3-bis(2-chloroethyl)-1-nitrosourea and 1-(2-chloroethyl)-3(2-hydroxyethyl)-1-nitrosourea. A crystallographic analysis. Eur J Biochem 17, 193-8.

18. Dubler RE, Anderson BM. (1981) Simultaneous inactivation of the catalytic activities of yeast glutathione reductase by $\mathrm{N}$-alkylmaleimides. Biochim Biophys Acta - Enzymology 659, 70-85.
19. Li Y, Trush MA. (1993) Oxidation of hydroquinone by copper: chemical mechanism and biological effects. Arch Biochem Biophys 300, 346-55.

20. Sadik CHD, Sies H, Schewe T. (2003) Inhibition of 15-lipoxygenases by flavonoids: structure-activity relations and mode of action. Biochem Pharmacol 65, 773-81.

21. Dickancaité E, Nemeikaitè A, Kalvelytè A, Cènas N. (1998) Prooxidant character of flavonoid cytotoxicity: structure-activity relationships Biochem Molecul Biol Int 45, 923-30. 